Portland State University

PDXScholar

Counselor Education Faculty Publications and

Presentations

Counselor Education

2000

\title{
Locus of control orientation and acceptance of disability
}

Hanoch Livneh

Portland State University

Erin Martz

University of Arkansas

Joseph Turpin

California State University - San Bernardino

Follow this and additional works at: https://pdxscholar.library.pdx.edu/coun_fac

Part of the Counseling Psychology Commons, and the Experimental Analysis of Behavior Commons Let us know how access to this document benefits you.

Citation Details

Martz, E., Livneh, H., Turpin, J. (2000). Locus of control orientation and acceptance of disability. Journal of Applied Rehabilitation Counseling, 31(3), 14-21.

This Article is brought to you for free and open access. It has been accepted for inclusion in Counselor Education Faculty Publications and Presentations by an authorized administrator of PDXScholar. Please contact us if we can make this document more accessible: pdxscholar@pdx.edu. 


\title{
Locus of Control Orientation and Acceptance of Disability
}

\author{
Erin Martz \\ Hanoch Livneh \\ Joseph Turpin
}

\begin{abstract}
The purpose of this study was to determine if differences existed in acceptance of disability scores between individuals with internal locus of control and external locus of control orientations. Ninety-seven out of 200 randomly-chosen participants with disabilities from a southern California community college completed the Reactions to Impairment and Disability Inventory (RIDI), Rotter's I-E Locus of Control Scale, and a demographic profile sheet. Acceptance of disability was defined as both acknowledgment and adjustment to a disability. Adjustment scores were found to be higher among those with an internal locus of control orientation but only among participants with mental/psychiatric disabilities. Also, differences in adjustment scores were found to be influenced by the domain of locus of control items. Implications for theory and research are briefly suggested.
\end{abstract}

$\mathrm{R}$ ehabilitation has been depicted as the third stage, called "tertiary intervention," in a multi-level model of therapeutic interventions. Three components typically make up the rehabilitation intervention. They include the minimization of the impact of disability, the compensation for disability by skill development, and the manipulation of environmental conditions to lessen their impact upon the medical, psychosocial and vocational aspects of an individual's life (Caplan, 1964; Cowen, 1973; Goodyear, 1976; Hershenson, 1990; Livneh, 1995; Wright, 1980). This intervention model provides a framework for viewing the research goals of this study. Two of the three components of tertiary intervention were investigated - acceptance of disability, which is reflected in the process of disability minimization, and locus of control, which is described as the individual's perceptions of control over reinforcements and reflects the belief in the ability to manipulate environmental conditions affecting the individual.

Prior research has, indeed, demonstrated a relationship between locus of control and acceptance of a disability. Mazzulla (1981) found that locus of control scores for individuals with spinal cord injuries became more internal as their acceptance of disability increased. In a longitudinal study, Brooks and Matson (1982) found that individuals with multiple sclerosis, who had more internal locus of control scores, also had more positive adjustment scores. Poll and De-Nour (1980) found that individuals with chronic hemodialysis who had more internal locus of control scores had significantly higher acceptance of disability scores than those with external locus of control scores. Moore, Stambrook, and Wilson (1991), based on their findings, concluded that in their sample of male patients who survived traumatic brain injury, lower internal locus of control scores and stronger beliefs in chance occurrences were associated with poorer quality of life outcomes, as evident by measures of psychosocial adaptation, mood disturbance, and depression. Finally, in a comparative study of two groups of participants with spinal cord injury and multiple sclerosis, the authors (MacLeod \& MacLeod, 1998) concluded that although internality was not related to measures of depression or anxiety in either group, externality was significantly associated with depression in the participants with spinal cord injury and approached significance for those with multiple sclerosis.

Rotter (1966) initially proposed that an external locus of control "may suggest, at least in our culture, a defensiveness related to significant maladjustment" (p. 16). It may, therefore, be hypothesized that an external locus of control orientation would also be associated with (a) less willingness to accept the reality of a disabling condition, as well as (b) lower overall adjustment to the disability.

Research has also demonstrated that locus of control may be related to the individual's coping behaviors. Parkes (1984) reported that individuals with more internal locus of control scores had an overall better degree of direct coping and a lower degree of suppression during stressful situations than individuals with a more external locus of control. Strickland (1978) summarized research, which indicated that individuals with an internal locus of control were more 
likely to take steps to change aversive life situations than individuals with an external locus of control. Finally, research has also shown that in individuals with spinal cord injuries, external perceptions of control, maladaptive coping styles, and lower self-esteem are intimately associated (Craig, Hancock, \& Chang, 1994). Before discussing the controversy about the construct of locus of control, the concept of acceptance of disability will be briefly reviewed.

\section{Acceptance of Disability}

Many definitions of acceptance of disability have been proposed. The terms acceptance and adjustment are often used indistinguishably from each other in the rehabilitation and disability studies literature. Acceptance of disability is, at times, viewed as an undesirable or negative state (e.g., resignation to impact of the condition), but also as an optimal, positive state and a process of continuous coping with a disability (Roessler \& Bolton, 1978; Scofield, Pape, McCracken, \& Maki, 1980; Thoreson \& Kerr, 1978; Wright, 1983). Livneh and Antonak (1990, 1991, 1997) distinguished between two types of acceptance. They designated the cognitive or intellectual type of acceptance of a disability as "acknowledgment." In contrast, they termed the emotional component of acceptance of a disability as "adjustment." More specifically, they defined intellectual acceptance, or acknowledgment, as a state of cognitive reorganization and reorientation demonstrated by: a) an acceptance of oneself as a person with a disability, b) a new sense of self-concept, c) a reappraisal of life values, and d) a search for new meanings and goals. Adjustment to a disability involved an emotional acceptance and a "sociobehavioral reintegration" that was reflected by: a) a positive self-worth, b) a realization of one's remaining and new potentialities, c) active pursuit and implementation of social and vocational goals, and d) when pursuing these goals, overcoming the obstacles that arise (Livneh \& Antonak, 1997 , p. 22). Hence, acknowledgment and adjustment, as dual aspects of acceptance, constituted the final two phases of a successful psychosocial adaptation process to disability.

\section{Locus of Control}

Locus of control has been extensively researched over the past four decades since Phares (1955), James (1957), Rotter, Seeman, and Liverant (1962), and Rotter (1966) began to investigate differences in individuals' perceptions of influence in their worlds. The first locus of control scales (James, 1957; Phares, 1955) were designed to study skill-chance situations. These early studies defined the internal locus of control orientation as the tendency to attribute events occurring in one's life to skill. Believing that chance determined the events in one's life was called an external locus of control in Phares' (1955) and James' (1957) studies.

This original focus on attributions of skill versus chance developed into studies of the perception of control of the positive or negative reinforcements that followed one's behavior. Many researchers who utilized the locus of control construct did not make a clear distinction between the con- cept of attributions, which were contained in the first locus of control studies, and the concept of reinforcements of behavior. Rotter (1966) was the first to suggest that locus of control was a belief about control over reinforcements. Specifically, he argued that:

\begin{abstract}
When a reinforcement is perceived by the subject as following some action of his own but not being entirely contingent upon his action, then, in our culture, it is typically perceived as the result of luck, chance, fate, as under the control of powerful others, or as unpredictable because of the great complexity of the forces surrounding him ... we have labeled this a belief in external control. If the person perceives that the event is contingent upon his own behavior or his own relatively permanent characteristics, we have termed this a belief in internal control (p. 1).
\end{abstract}

Gurin, Gurin, Lao, and Beattie (1969, p. 29) defined internal locus of control as "a person's belief that rewards follow from, or are contingent upon, his own behavior." An external control was viewed as "a belief that rewards are controlled by forces outside himself and thus may occur independent of his own actions" (Gurin et al., 1969, p. 29). Friedman, Goodrich, and Fullerton (1985) rephrased Rotter's perspective to describe an internal locus of control as a perception that the reinforcements or rewards, which individuals experienced, depended upon their own actions, characteristics, or skills. In contrast, individuals with an external locus of control believed that the reinforcements or rewards following their actions were not related to their choices but were controlled by external agents like chance or powerful others (Friedman et al., 1985).

The construct of locus of control should be distinguished from the concept of control over causality, or the attribution of responsibility for an event. Pettersen (1987) described the difference between locus of control and causal attribution by noting that the latter was "an individual's perceiving of a given determinant as a cause of what happens to him," while locus of control, or "behavioral outcome contingency," was an individual's "believing that he can control what happens to him" (p. 204). Zuroff (1980) proposed the following argument to distinguish control from attribution concepts. Locus of control is evaluated before an outcome has happened while attributions are evaluated afterwards. Further, internal-external in Rotter's theory refers to whether the outcome is perceived as contingent or non-contingent upon one's behavior, while in attribution theory, internal-external refers to whether the cause originates from inside or outside the person (Zuroff, 1980). It can, therefore, be said that attribution theories examine whether individuals perceive to be in control of or responsible for the occurrence of a past event in their lives. Locus of control, in contrast, is viewed as a pre-action expectancy to have control of the reinforcements or rewards that may follow one's primary actions or behaviors.

Attribution of causality is often not distinguished from locus of control, especially when the term "control" is utilized in attribution theories. H.M. Lefcourt, who has 
written several volumes on locus of control research, is reported to blend the concepts of locus of control with causal attribution (Palenzuela, 1984; Petterson, 1987). Other researchers who have created instruments purportedly to measure locus of control have not kept locus of control distinct from other related constructs (Palenzuela, 1988). For example, Sue's (1978) locus of responsibility, which describes four kinds of world-views based on an individualsystem blame and control dimensions, also utilizes locus of control as a type of attribution concept.

Bandura's (1977) concept of self-efficacy also shares similar conceptual elements with locus of control. Yet, Bandura (1977) defines self-efficacy as a mastery expectation that "one can successfully execute the behavior required to produce the outcomes" (p. 79). Wallston, Wallston, Smith, and Dobbins (1987, p. 9) describe self-efficacy as "the person's belief that he/she can engage in a specific behavior." Thus, while locus of control refers to the perception of who or what controls the reinforcements or rewards that follow events or actions in one's life, selfefficacy refers to whether or not an individual perceives to have the power to execute a specific, primary action or behavior in the present or future.

Wallston, Wallston, Smith, and Dobbins (1987) propose "perceived control" as a construct encompassing locus of control, self-efficacy, and attribution theories to explain perceptions of control in health. Though Wallston et al. (1987) make a distinction between locus of control and self-efficacy and between self-efficacy and attribution, their proposed "central psychological construct" (p. 21) of perceived control attempts to explain health behaviors, processes, and outcomes by incorporating the constructs of locus of control, self-efficacy, and causal attribution into one construct.

In this study, we viewed control over one's behaviors in the past or the anticipation of control in the future (self-efficacy, causal attribution, or perceived control) as distinct from control over the reinforcements or rewards in one's life (locus of control). Pettersen (1987) clarifies the distinction, when he posits that locus of control is "the perception of being able or not being able to change the probability that a reinforcement might occur" (p. 206). Hence, an internal locus of control is a perception that one's behavior influences environmental conditions and more specifically, determines the occurrence of reinforcements following one's behavior. Palenzuela (1984) offers a slightly different focus to locus of control, describing it as an "expectancy of contingency versus noncontingency between behavior and outcomes" (p. 698). The emphasis in Palenzuela's definition is whether an individual makes a connection between behavior and outcomes, or outcome expectancy. Thus, whereas Pettersen depicts locus of control as a perception of control over the occurrence of reinforcements by increasing the probability that they will occur (internal locus of control), Palenzuela describes locus of control as whether the individual perceives a cause-effect relationship between behavior and outcomes/reinforcements.
An internal locus of control may also be regarded as the control of reinforcements by means of the individual's abilities to control attitudes about what is reinforcing (i.e., control over personal values, expectancies, and attitudes). In view of the fact that a wide range of potential reinforcements occurs in the environment simultaneously with peoples' behaviors, reinforcements acquire their reinforcing power because they are commensurate with the individual's values or desires. Therefore, an internal locus of control indicates that the individual has control over reinforcements, due to the ability to choose and modify what he or she believes to be reinforcing. When an individual realizes this control, then the limitations or barriers, such as caused by a physical impairment, can be reframed as the individual establishes new goals and values. Consequently, individuals' acceptance of disability, as indicated by both acknowledgment and adjustment to disability, can be examined in view of this definition of locus of control as representing an attitudinal control over what is or is not reinforcing. This proposed explanation of locus of control shifts Pettersen's (1987) focus from the behavioral and environmental aspects of locus of control (which emphasizes the perception of control over the occurrence of reinforcements by a control over "the probability that a reinforcement might occur"; p. 206), to a perception of control over what one believes to reinforce one's behavior out of the many potential reinforcers in the environment. Hence, the occurrence of reinforcers - or the expectations of a certain outcome - is not essential to the proposed definition of locus of control, since a wealth of potential reinforcers exist in one's environment and multiple reinforcers can encourage one specific behavior to reoccur. Instead, the focus is on the control of reinforcers by means of the individual's ability to control what constitutes a reinforcement. For example, if an individual keeps a job because of its high salary, then from an internal locus of control perspective, it may be assumed that the individual realizes that he or she permits money to be a reinforcement, because of its financial value. If money was valued as a weaker reinforcer than job satisfaction, then an internal locus of control orientation may prompt the individual to find a more satisfactory job, though it may result in lower pay. Hence, the individual is controlling what he or she permits to act as a reinforcer to his or her behavior. In this example, the question of self-efficacy - whether the individual can obtain a more satisfactory job - is not a material factor. Instead, it is the attitudinal control over the reinforcers of a behavior, which in this example was money that encouraged the individual to maintain the behavior (job).

In accordance with the above discussion, this study attempted to address the following research questions:

1. Are there differences in adjustment scores (as indicators of emotional acceptance of disability and behavioral implementation of newly developed goals) and acknowledgment scores (as indicators of cognitive acceptance of disability) between participants with an internal locus of control and those with external locus of control (LOC)? It was hypothesized that 
participants with an internal LOC orientation would exhibit higher levels of adjustment and acknowledgment than those with an external LOC.

2. Are differences in levels of adjustment and acknowledgment, for participants with internal vs. external LOC orientations, being manifested differently for those whose primary disability is mental/psychiatric rather than physical/sensory in origin? The available literature on LOC orientation and adaptation to chronic illness and disabilities has focused predominantly on the relationship between these two measures among participants with physical disabilities (e.g., cancer, heart conditions, spinal cord injury, multiple sclerosis). It was, therefore, hypothesized that since LOC is regarded as a rather stable personality disposition, higher levels of internal LOC would be associated with increased degrees of adjustment and acknowledgment, irrespective of the type of disabling condition.

3. Are differences in levels of adjustment and acknowledgment, for participants with internal vs. external and personal vs. social-political LOC orientations (creating 4 groups of respondents) being manifested differently for those whose primary disability is mental/psychiatric rather than physical/sensory in origin? Since the available literature suggests that LOC may not be unidimensional in nature (i.e., it may be comprised of more than a single internal-external continuum) it was deemed important to explore how two primary components of LOC (namely, personal and social-political) may interact with type of disability to influence levels of adjustment and acknowledgment. No specific predictors were made in regard to the latter research question.

\section{Method}

\section{Participants}

Two hundred participants were randomly selected from a pool of 596 individuals, who were registered in a community college's program for students with disabilities in southern California. From the 200 participants who were contacted by mail, a total of 100 participants responded. Fifty-four participants responded to the first mailing of the research instruments. A second mailing to 146 non-respondents elicited 46 additional responses. Of the 100 returned research instruments, useable data were available for a total of 97 respondents (e.g., two respondents, each, completed only one of the two measures and the third respondent omitted a large amount of data).

The mean age of the respondents was 36.47 years $(S D=12.23 \mathrm{yrs}$.), with a range of 17 to 74 years. The mean age of onset of disability was 16.12 years $(S D=14.71$ yrs.) with a range of 0 to 55 years. Mean disability duration was 20.03 years $(S D=14.52$ yrs.) with a range of 1 to 54 years.
Fifty-seven participants were female (59.4\%) and 39 participants were male $(40.6 \%)$, with one participant declining to answer. Ethnic backgrounds reported included: White (47.4\%); Hispanic (28.4\%); African-American (17.9\%); Asian-American (1.1\%); American-Indian (3.2\%); and Other $(2.1 \%)$. Marital status of the participants included: single $(55.2 \%)$; married $(17.7 \%)$; separated $(8.3 \%)$; divorced (15.6\%); and widowed (3.1\%). Causes of disability included: birth disorders $(42.9 \%)$; accident $(23.1 \%)$; illness $(17.6 \%)$; other $(16.5 \%)$. The type of primary disability reported included: physical/visible (19.3\%); physical/invisible (30.7\%); learning (25.0\%); and psychiatric disabilities $(25.0 \%)$. In response to the question, "Can an observer tell that you have a disability?" $79.2 \%$ reported to have an invisible disability, while $20.8 \%$ reported a visible disability. Educational status was reported as: high-school education $(57.4 \%) ; 1-2$ years of college $(34.0 \%) ; 3$ or more years of college (5.3\%); a bachelor's degree (2.1\%); and more than a bachelor's degree $(1.1 \%)$.

\section{Instruments}

The Reactions to Impairment and Disability Inventory (RIDI) (Livneh \& Antonak, 1989) is a 60-item multidimensional scale to measure psychosocial adaptation to disabling conditions. It provides scores on the following subscales: Shock, Anxiety, Denial, Depression, Internalized Anger, Externalized Hostility, Acknowledgment, and Adjustment. Cronbach's alpha values for the eight subscales were reported to range from 0.69 to 0.85 (Livneh \& Antonak, 1997). Two of the eight subscales of the RIDI were selected for this study - Acknowledgment and Adjustment. The Acknowledgment scale contains 7 items with a range of 7 to 28 . The Adjustment scale consists of 8 items with a range of 8 to 32 .

The Internal-External (I-E) Locus of Control Scale (Rotter, 1966) is a unidimensional scale that includes 23 paired items with six additional filler items. The I-E Scale provides a single score that reflects locus of control perceptions, ranging from 1 to 23 . Higher scores depict an external locus of control orientation. For this study, those scoring 1-to-8 $(n=45)$ comprised the "internal" group, while those scoring 9-to-18 (n=52) made up the "external" group. Internal consistency (Kuder-Richardson) was reported as .70 (Rotter, 1966). Test-retest values were reported to range from .55 to .72 (Rotter, 1966). Since other research (e.g., Berzins \& Ross, 1973; Parkes, 1985; Watson, 1981) raised doubt about the unidimensionality of the LOC Scale, it was decided to also create two separate subscales in accordance with previous research; namely "personal control" and "socio-political control." Scores were summed up to yield separate subscale scores for each of the two.

A form requesting demographic data was also mailed to participants and included a question on the type of primary disability and the following question on the visibility of disability: "Can an observer tell by looking at you that you have a disability?" 


\section{Procedure}

The two instruments, the demographics data-sheet, and an informed consent form were mailed to participants, accompanied by a white envelope that was stamped "confidential" and a stamped envelope that was addressed to the community college's program for students with disabilities. Instructions were included to place the forms in the envelope marked "confidential" and then return that envelope with the consent form in the stamped, addressed envelope to ensure participants' response-anonymity. Instructions were also given for those individuals who had a learning disability, and not a physical disability, to mark "Reaction is Never Experienced" for those questions on the RIDI that asked specifically about a physical disability. A coupon for a free meal at a local hamburger chain was sent to all respondents.

\section{Results}

To answer the first research question, an independent samples t-test was first performed to detect the presence of significant differences between the mean adjustment scores of participants with internal locus of control scores and the mean adjustment scores of individuals with external locus of control scores. A non-significant statistical difference, $t(95)=1.79, p=.07$, was found between adjustment scores of participants with an internal locus of control and those participants with an external locus of control. Participants with an internal locus of control had higher, but not statistically significant, adjustment scores $(M=22.82 ; S D=5.95)$ than individuals with an external locus of control $(M=20.71$; $S D=5.65$ ). Next, an independent samples t-test was performed to detect the presence of significant differences between the mean of acknowledgment scores of participants with internal locus of control scores and the mean of acknowledgment scores of participants with external locus of control scores. Again, no significant difference was found between acknowledgment scores of participants with an internal locus of control and participants with an external locus of control, $t(95)=1.17, p=.24$ (ns).

To address the second research question, independent samples t-test procedures, for both adjustment and acknowledgment scores of internally- vs. externally-orientated respondents, were applied separately to those participants with physical/sensory disabilities ( $n=44)$ (e.g., blindness, cerebral palsy, epilepsy, hearing impairment, heart disease, kidney failure, muscular dystrophy, paraplegia) and those with mental/psychiatric disabilities $(n=44)$ (e.g., depression, learning disabilities, obsessive-compulsive disorder, schizophrenia). Neither of the two acknowledgment t-test values (for either group of participants) reached statistical significance, although in both cases those with internal LOC scored higher, on the average, than those with external LOC. When applied to the two groups of participants' adjustment scores, a significant $t$-test value was observed for those with mental/psychiatric disabilities $[t(42)=2.41, p=.02]$, but not for those with physical/sensory disabilities $[t(42)=0.44$ $(n s)]$.

To address the third and final research question four separate 2-way analyses of variance were performed. The first used scores on the acknowledgment scale as the dependent variable, while type of disability (physical vs. mental), social-political LOC (internal vs. external; again, dichotomized at the distribution's median), and their interaction effect served as the independent variables. The second analysis, again, used scores on the acknowledgment scale as the dependent variable, but scores on the personal LOC replaced those of the social-political LOC as one of the independent variables. In both of the acknowledgment analyses no main effects were found for type of LOC, type of disability, or their interaction.

The third and fourth analyses repeated the previous analyses but with scores on the adjustment scale serving as the dependent variable. Although no main or interaction effects were evident when the personal LOC served as an independent variable, a statistically significant effect was found for the social-political LOC $[F(1,95)=5.72, p=.019]$. Thus, the mean adjustment scores for those with internal social-political LOC were higher than for those with external social-political LOC regardless of disability type ( $M=$ 23.22 and $M=20.69$, respectively).

\section{Discussion}

If internal locus of control is regarded as a generalized perception of control over one's attitudes toward what is and what is not reinforcing, then the results of this study become somewhat clearer. In this study, individuals with an internal LOC were found to have higher adjustment scores than individuals with an external LOC, but only under certain conditions. Although differences, in mean adjustment scores, between internally- and externally-oriented participants with disabilities just failed to reach statistical significance $(p=.07)$, these differences became more apparent when participants' type of disability (i.e., mental/psychiatric) and LOC-specific attributes (i.e., social-political) were isolated. It can be argued that since adjustment to disability is a complex, dynamic, and multifaceted concept (e.g., it includes both affective and behavioral components, it focuses on both present positive self-worth and realization of future potentialities), its relationship to LOC orientation would be mediated by a variety of demographic, disabilityrelated, and other personality attributes. In the present sample of young (mean age of 36 years), educated (community college students), and relatively long-term disabled (mean disability duration of 20 years) participants, it is possible that perceptions of locus of control were mediated differently by disability-specific variables and contribute more to level of adjustment among those with mental disabilities who may have to overcome a wider range of emotional, behavioral, learning, and attitudinal barriers than those with physi$\mathrm{cal} /$ sensory disabilities. It is equally conceivable that differ- 
ences in adjustment scores, as filtered through perceptions of LOC, were more pronounced for those with mentalpsychiatric disabilities because the items on the RIDI's adjustment scale were approached differently by the two groups. Indeed, mean adjustment scores were significantly higher $(p<.05)$ for those with mental/psychiatric disabilities $(M=$ $23.05)$ than for those with visible physical disabilities $(M=$ 19.35) and also for respondents with learning disabilities $(M=19.59)$. This may suggest one of two possibilities. First, since the RIDI is intended to measure adjustment and other psychosocial reactions to physical disabilities following the onset of typically specific environmental or biomedical conditions, it may not be sensitive to addressing the more protracted and nonspecific challenges in the process of adaptation to a mental condition. Second, it is also possible that those with physical disabilities are less influenced by "social desirability" needs, are more aware of their limitations, and are willing to endorse those items suggesting existing issues more openly than participants whose primary disability is mental/psychiatric in nature.

As to the finding that only the social-political, but not the personal, subscale of Rotter LOC Scale was related to adjustment scores, irrespective of disability type, inspection of the content of the two subscales may help to clarify this perplexing finding. The items that comprise the personal LOC subscale are mostly phrased in first person and often focus on the belief that one's ability, rather than luck or fate, is a material factor in future success and advancement (personal, internal LOC). In contrast, the social-political subscale is made up mostly of items that generally depict beliefs about the causal relationships concerning the ability of members of society to influence government and other large social systems (Lefcourt, 1991). As such, it is more closely associated with people's impact on such programs as the vocational rehabilitation system and politically-based efforts such as the Americans with Disabilities Act.

Within this context, it may be argued that level of adjustment is more intimately associated with the belief in people's ability to exert influence on macrosystemic, sociopolitical programs, rather than merely on an individualized course of action. More specifically, when responding to items on the Rotter LOC Scale, people with disabilities, who demonstrate higher levels of psychosocial adjustment, are able to realize the existing opportunities of successfully influencing the course of government-operated programs (e.g., "the average citizen can have an influence in government decisions"; "with enough effort we can wipe out political corruption"). At the same, they might be sufficiently realistic in accepting the restrictions imposed upon individuals because of the occurrence of certain unpredictable life events ("most misfortunes are the result of lack of ability, ignorance, laziness, or all three" ; "it is impossible for me to believe that chance or luck plays an important role in my life").

Although the findings of this study suggest that students with disabilities who adopt an internal LOC are better adjusted only when certain disability-related and LOC-specific components are considered, they nevertheless affirm the distinction between adjustment to and acknowledgment of disability. The affective reorientation of values (adjustment) parallels that of the internal LOC orientation of control over one's attitudes toward what is and is not reinforcing. Thus, just as an internal LOC orientation entails the ability to alter what is or is not reinforcing (at least within the social, vocational, and political domains), so does the process of successful adaptation to disability involves the individual's ability to shift what is valued, needed, and desired as one gradually incorporates a new identity into the former self.

The lack of significant differences (although all differences were in the predicted direction) between the mean acknowledgment scores of participants with internal and external LOC, can be partially explained by examining the concept of acknowledgment as measured by the RIDI. Acknowledgment is perceived as the intellectual acceptance of a disabling condition with a cognitive integration of the functional limitations of the impairment, including the first steps toward forming a new self-identity (Livneh \& Antonak, 1990, 1991, 1997). The reappraisal of life values and a search for new meanings and goals reflect a cognitive reframing by the individual with disability. The ability to cognitively reframe situations (to acknowledge) is, therefore, distinct from adopting an internal LOC orientation. The latter reflects the individual's attitudinal conviction of controlling environmental reinforcements, or rewards, and hence requires the engagement of both affective and behavioral orientation to disability management.

\section{Limitations}

The preliminary findings of this study must be interpreted with caution due to a number of limitations. First, this study is based on a small sample of participants with disabilities at a community college in southern California, and therefore has limited generalizability. The nearly equal percentage of people with learning disabilities, physical invisible disabilities, physical visible disabilities, and mental disabilities indicates that this group may represent a good cross-section from the community college population, who have signed up with or utilized the services to students with disabilities on the community college campus. Yet, other groups, such as those with invisible disabilities, may have remained unidentified in the community college setting. The unidentified individuals with disabilities may have not sought help with the campus Disabled Students Services and Programs, because they were not aware of the availability of these services or elected not to disclose the existence of a disability with university officials. It is also possible that these unidentified individuals with disabilities felt no need to seek academic assistance in areas where they felt confident of achieving success. Secondly, the educational homogeneity of the participants restrict the generalizability of findings to groups with other educational backgrounds. Thirdly, due to the cross-sectional and non-experimental research design of this study, no cause-effect relationships can be established 
from the findings obtained in this study. The study of the causal nature of the relationships between locus of control and acknowledgment and adjustment of disability, therefore, requires the adoption of a longitudinal research design. Finally, the emergence of only two statistically significant differences among the several comparisons undertaken must also be interpreted with caution, since no strict adherence to Type I error minimization (e.g., the Bonferroni procedure) was followed in this study.

\section{Directions for Future Research}

Future model-building and research efforts need to focus more squarely on the elaborate relationships between locus of control and adjustment to disability. Among many of the questions left unanswered by the present study are: (a) Since previous research has uncovered other dimensions of LOC (powerful others, chance, social-political; Lefcourt, 1991), researchers should explore in greater detail the bi-directional nature of the relationships between perceived control and adjustment to disability - how do these two psychosocial mechanisms relate to each other and under what disabilityrelated and environmental conditions do these relationships tend to be accentuated? (b) if locus of control is perceived as a trait-like coping mode, how does it interact with more specific, state-like coping strategies (e.g., problem-solving, seeking social support, wishful thinking) to influence adaptation to disability? (c) if type of disabling condition does, indeed, influence the nature and process of adaptation to disability and if this influence is mediated by, among others, such variables as LOC, then theory and research must focus on investigating these complex relationships and untangle their dynamic nature; and (d) could an indi vidual's score on LOC, or any of its dimensions, predict not merely scores on adjustment, but of the pattern, duration, and other reactions typically experienced following the onset of disability (e.g., depression, denial, anger)?

Drawing clinical implications from the preliminary and sample-specific findings of this study are premature. It may be argued, however, that if positive relationships between internal locus of control, or any of its domains, and successful adjustment to disability are confirmed by future research, then the following intervention goals are warranted: (a) Promoting and rewarding the use of a more internal locus of control orientation among rehabilitation clients, (b) challenging and confronting "external statements," and (c) assisting the client in recognizing the contingencies of his or her behavior by questioning what could be done now and in the future to cope with specific problems (see also, Joe, 1971; MacDonald, 1972).

It is commonly believed that successful psychosocial adaptation to disability may be fostered by helping individuals realize their ability to exert control over what they believe to be reinforcing in their lives (Livneh, 1986; Roessler \& Bolton, 1978; Wright, 1983). If an internal locus of control orientation is, indeed, helpful in accepting and integrating disability in its fullest sense, then it may be argued that promoting the belief in one's control not only over attitudes toward the self, but also over what is valued in life becomes the ultimate mission of rehabilitation.

\section{References}

Bandura, A. (1977). Social learning theory. Englewood Cliffs, NJ: Prentice Hall.

Berzins, J.I., \& Ross, W.F. (1973). Locus of control among opiate addicts. Journal of Consulting and Clinical Psychology, 40, 84-91.

Brooks, N.A., \& Matson, R.R. (1982). Social-psychological adjustment to multiple sclerosis. Social Science \& Medicine, 16 , 2129-2135.

Caplan, G. (1964). Principles of preventive psychiatry. New York: Basic Books.

Cowen, E.L. (1973). Social and community interventions. Annual Review of Psychology, 24, 423-472.

Craig, A.R., Hancock, K., \& Chang, E. (1994). The influence of spinal cord injury on coping styles and self-perceptions two years after the injury. Australian and New Zealand Journal of Psychiatry, 28, 307-312.

Friedman, R., Goodrich, W., \& Fullerton, C.S. (1985). Locus of control and severity of psychiatric illness in the residential treatment of adolescents. Residential Group Care and Treatment, 2 (2), 3-13.

Goodyear, R.L. (1976). Counselors as community psychologists. Personnel and Guidance Journal, 54, 512-516.

Gurin, P., Gurin, G., Lao, R.C., \& Beattie, M. (1969). Internal-external control in the motivational dynamics of Negro youth. Journal of Social Issues, 25, 29-53.

Hershenson, D.B. (1990). A theoretical model for rehabilitation counseling. Rehabilitation Counseling Bulletin, 33 (4), 268278.

James, W.H. (1957). Internal versus external control of reinforcement as a basic variable in learning theory. Unpublished doctoral dissertation, Ohio State University, Columbus.

Joe, V.C. (1971). Review of the internal-external control construct as a personality variable. Psychological Reports, 28, 619640.

Lefcourt, H.M. (1991). Locus of control. In J.P. Robinson, P.R. Shaver, \& L.S. Wrightsman (Eds.), Measures of personality and social psychological attitudes (vol. 1). (pp. 413-499). New York: Academic Press.

Livneh, H. (1986(. A unified approach to existing models of adaptation to disability: Part la models of adaptation. Journal of Applied Rehabilitation Counseling, 17 (1), 5-17, 56.

Livneh, H. (1995). The tripartite model of rehabilitation intervention: Basics, goals, and rehabilitation strategies. Journal of Applied Rehabilitation Counseling, 26 (1), 25-29.

Livneh, H., \& Antonak, R.F. (1990). Reactions to disability: An empirical investigation of their nature and structure. Journal of Applied Rehabilitation Counseling, 21 (4), 13-21.

Livneh, H., \& Antonak, R. (1991). Temporal structure of adaptation to disability. Rehabilitation Counseling Bulletin, 34 (4), 298-318.

Livneh, H., \& Antonak, R. (1997). Psychosocial adaptation to chronic illness and disability. Gaithersburg, MD: Aspen Publishers.

MacDonald, A.P., Jr. (1972). Internal-external locus of control change-technics. Rehabilitation Literature, 33, 44-47.

MacLeod, L., \& MacLeod, G. (1998). Control cognitions and psychological disturbance in people with contrasting physically disabling conditions. Disability and Rehabilitation, 20, 448-456.

Mazzulla, J.R. (1981). The relationship between locus-of-control expectancy and acceptance of acquired traumatic spinal cord 
injury. Unpublished MA thesis, East Carolina University, Greenville, North Carolina.

Moore, A.D., Stambrook, M., \& Wilson, K.G. (1991). Cognitive moderators in adjustment to chronic illness: Locus of control beliefs following traumatic brain injury. Neuropsychological Rehabilitation, 1, 185-198.

Palenzuela, D.L. (1984). Critical evaluation of locus of control: Toward a reconceptualization of the construct and its measurement. Psychological Reports, 54, 683-709.

Parkes, K.R. (1984). Locus of control, cognitive appraisal, and coping in stressful episodes. Journal of Personality and Social Psychology, 46, 655-668.

Parkes, K.R. (1985). Dimensionality of Rotter's Locus of Control Scale: An application of the "very simple structure" techniques. Personality and Individual Differences, 6, 115-119.

Pettersen, N. (1987). A conceptual difference between internal-extemal locus of control and causal attribution. Psychological Reports, 60, 203-209.

Phares, E.J. (1955). Changes in expectancy in skill and chance situations. Unpublished doctoral dissertation, Ohio State University, Columbus.

Poll, I.B., \& De-Nour, A.K. (1980). Locus of control and adjustment to chronic hemodialysis. Psychological Medicine, 10, 153-157.

Roessler, R., \& Bolton, B. (1978). Psychosocial adjustment to disability. Baltimore, MD: University Park Press.

Rotter, J. (1966). Generalized expectancies for internal versus external control of re inforcement. Psychological Monographs, 80 (1, Whole No. 609).

Rotter, J., Seeman, M., \& Liverant, S. (1962). Internal versus external control of reinforcement: A major variable in behavior theory. In N.F. Washburne (Ed.), Decisions, values and groups, (vol. 2). London: Pergamon Press.

Scofield, M.E., Pape, D.A., McCracken, N., \& Maki, D.R. (1980). An ecological model for promoting acceptance of disability. Journal of Applied Rehabilitation Counseling, 11 (4), 183187.
Strickland, B.R. (1978). Internal-external expectancies and health-related behaviors. Journal of Consulting and Clinical Psychology, 40, 1192-1211.

Sue, D.W. (1978). World views and counseling. Personnel and Guidance Journal, (4), 458-462.

Thoreson, R.W., \& Kerr, B.A. (1978). The stigmatizing aspects of severe disability: Strategies for change. Journal of Applied Rehabilitation Counseling, 9 (2), 21-26.

Wallston, K.A., Wallston, B.S., Smith, S., \& Dobbins, C.J. (1987). Perceived control and health. Current Psychological Research and Reviews, 6, 5-25.

Watson, J.M. (1981). A note on the dimensionality of the Rotter Locus of Control Scale. Australian Journal of Psychology, 33, 319-330.

Wright, B.A. (1983). Physical disability: A psychosocial approach (2nd ed.). N.Y.: Harper and Row.

Wright, G.N. (1980). Total rehabilitation. Boston: Little, Brown.

Zuroff, D.C. (1980). Learned helplessness in humans: An analysis of learning processes and the roles of the individual and situational differences. Joumal of Personality and Social Psychology, (39), 130-146.

Acknowledgments: The authors would like to thank Dudley Wiest, Ph.D. of California State University, San Bernardino for his input on the first author's M.A. thesis, upon which this article is based. Appreciation is also extended to the Associated Students, Inc. of California State University for providing support for incurred research costs, to Rebeccah Warren-Marlatt of San Bernardino Community College for help with data collection, and to Baker's Burgers, Corporation for providing incentives for participants of this research project.

Erin Martz, MA, CRC, University of Arkansas, Fayetteville.

Hanoch Livneh, Ph.D., CRC, Portland State University.

Joseph Turpin, Ph.D., California State University, San Bernardino. 